\title{
Anti-oxidant and anti-inflamatuar effectiveness of caftaric acid on gastric ulcer induced by indomethacin in rats
}

\author{
Ayhan Tanyeli ${ }^{1}$, Fazile Nur Ekinci Akdemir ${ }^{2}$, Ersen Eraslan ${ }^{3}$, Mustafa Can Güler ${ }^{1}$ and Tuncer \\ Nacar ${ }^{1}$ \\ ${ }^{1}$ Department of Physiology, Faculty of Medicine, Atatürk University, Erzurum, Turkey \\ ${ }^{2}$ Department of Nutrition and Dietetics, High School of Health, Ağri İbrahim Çeçen University, Ağri, Turkey \\ ${ }^{3}$ Department of Physiology, Faculty of Medicine, Bozok University, Yozgat, Turkey
}

\begin{abstract}
In this study, we evaluated the anti-oxidant and anti-inflammatory effect of caftaric acid against ulcer produced by indomethacin in gastric mucosa. Female Sprague Dawley albino rats were divided into five groups: control (saline group, $n=8$ ), negative control (indomethacin group, $n=8$ ), positive control (omeprazole group, $n=8$ ), low dose therapy (caftaric acid, $n=8$ ), and high dose therapy (caftaric acid, $n=8$ ). At the end of the experiment, all rats were sacrificed and gastric mucosa samples were removed for macroscopic and biochemical analysis. In our study, we detected that oxidant parameter values and cytokine levels increased in the negative control group, but total antioxidant status reduced, whereas, cytokine and oxidant parameter levels were significantly reduced due to low and high doses of caftaric acid administration. But another important point to note is that high dose caftaric acid therapy performed gastroprotective effect as omeprazole. In the macroscopic evaluation, there were reductions in ulcer sizes with a low and high dose of caftaric acid administration in contrast to the negative control group. As a result of our study, caftaric acid showed anti-oxidant and anti-inflammatory effects in indomethacin-induced gastric ulcer in rats.
\end{abstract}

Key words: Caftaric acid - Indomethacin - Omeprazole - Ulcer — Rat

\section{Introduction}

Gastric or peptic ulcer is defined as tissue loss in the stomach and duodenal mucosa due to non-steroidal antiinflammatory drugs (NSAIDs) such as aspirin or indomethacin, acid secretion, alcohol consumption, smoking, stress, hereditary predisposition, cortisone derivative drugs and viruses (Liu et al. 2015). Also, it has been introduced that gastric or peptic ulcer is a gastrointestinal disorder resulting from the disrupt of the balance between the protective and aggravating/damaging factors of the gastric mucosa (Brzozowski et al. 2005). NSAIDs are usually preferred as anti-inflammatory, analgesic and antipyretic agents, but they also lead to gastrointestinal damage, which causes severe complications including perforation, gastric

Correspondence to: Fazile Nur Ekinci Akdemir, Department of Nutrition and Dietetics, High School of Health, Ağri İbrahim Çeçen University, 04100, Ağri, Turkey

E-mail: fazilenur@yandex.com or duodenal ulcers and haemorrhage (Teichert et al. 2014). Moreover, it was declared that reactive oxygen species (ROS) generation and consumption of endogenous prostaglandins via the inhibition of cyclooxygenase enzyme is effective on the enlargement of the gastric mucosal lesions caused by indomethacin (Simmons et al. 2004; Kim et al. 2011). ROS are directly related to the inflammatory process activation in the injured gastric or duodenal tissues (Suleyman et al. 2010).

The strategies for the protection against gastric or peptic mucosal injury induced by NSAIDs have been totally successful as indicated in proton pump inhibitors (PPIs) (Wallace 2013). Drugs such as PPIs, for ex. omeprazole and lansoprazole, are mostly used in ulcer treatment. These drugs inhibit the function of proton pumps $\left(\mathrm{H}^{+} / \mathrm{K}^{+}\right.$ATPase $)$in the stomach irreversibly and stop the release of gastric acid into the gastric lumen (Richardson et al. 1998). Thus, repair of the ulcer area is supported. Unfortunately, long-term use of these inhibitors for decrease in gastric acid secretion cause chronic side effects (Wallace et al. 2011). There have 
been various studies about the side effects of PPIs-derived drugs. It has been reported that chronic use of PPIs in the postmenopausal period triggered bone fractures and bone dislocation (Gray et al. 2010). In addition, prolonged use of PPI-derived drugs is associated with numerous side effects such as increase in bacterial diarrhoea due to decreased gastric $\mathrm{pH}$, thinning in the gastric mucosa, vitamin B12 deficiency, hypomagnesaemia, and cardiac arrhythmias in non-cardiac patients depending on decrease in gastric secretion (Howden 2000; Yearsley et al. 2006; Cundy and Dissanayake 2008; Graham and Genta 2008; Niklasson et al. 2010).

In the recent years, numerous scientific researches have been conducted on various therapeutic agents in treatment of gastric ulcer which are less toxic than the drugs used in the clinic such as omeprazole and lansoprazole (El-Komya and Mouafib 2016; Gomaa et al. 2018; Pineda-Pena et al. 2018). Caftaric acid is the ester form of caffeic acid. This compound presents in some foods and beverages. It is reported that caftaric acid has hyaluronidase inhibitory activity, antioxidant and insulin secretion enhancing properties (Raso et al. 2002; Barrett 2003).

As a result of our literature reviews on Web of Science, it was not found any study about the effects of caftaric acid on gastric ulcer model induced by indomethacin. For this purpose, our study was planned to evaluate anti-inflammatory and antioxidant effects of caftaric acid on protection against experimental gastric ulcer model induced by indomethacin.

\section{Material and Methods}

\section{Drugs and animals}

Caftaric acid was obtained from Sigma Aldrich Chemical, USA. Thiopental sodium was purchased by (Pental Sodium IV Flakon) Uruguay, İstanbul, Turkey. Omeprazole (Omeprol $20 \mathrm{mg}$ ) was obtained from Sandoz Ürünleri İlaç Gida Kimya ve Tohum San. A.Ş. Turkey and indomethacin (Endostatin $25 \mathrm{mg}$ ) was purchased from Nobel İlaç Sanayi, İstanbul, Turkey.

This study was approved by Atatürk University Experimental Animal Ethics Committee (Date: 27.04.2018/ Number: 104) and the experiments were conducted at Atatürk University Experimental Animals Research and Application Center (ATADEM). Within the scope of our study, forty female Sprague Dawley albino rats $(220 \pm 10 \mathrm{~g})$ were housed in polypropylene cages under appropriate laboratory conditions such as humidity of 55\%, 12-h light/dark cycle and average $22^{\circ} \mathrm{C}$ degree temperature. All rats were fed with standard laboratory food and (provided tap) water. Rats had access to food and water ad libitum. However, all rats were fasted, with access only to clean water $24 \mathrm{~h}$ prior to the indomethacin induction and water access was prevented for $2 \mathrm{~h}$ before the indomethacin dosing.

\section{Experimental procedures and groups}

All rats were weighed and divided into five groups to be randomized (8 rats in each group). Groups have been constructed as follows:

Control group: $1 \mathrm{ml}$ of distilled water was applied orally gavage.

Negative control group: $100 \mathrm{mg} / \mathrm{kg}$ of indomethacin was administered to animals by single gavage as previously described in some studies (Zheng et al. 2014; Wu et al. 2018). 6 hours after the indomethacin administration, the animals in all groups were sacrificed by applying the high dose of anaesthetic agent (thiopental sodium $50 \mathrm{mg} /$ $\mathrm{kg}$ ) and the ulcerative gastric mucosa fields were excised. The samples were cleared of the gastric contents by washing in saline and photographed for macroscopic examination. Also, ulcer sizes were measured by millimetric paper. Then, tissue samples were maintained at $-80^{\circ} \mathrm{C}$ until the biochemical analyzes.

Positive control group: $30 \mathrm{mg} / \mathrm{kg}$ of omeprazole was administered by oral gavage $30 \mathrm{~min}$ before the indomethacin induction. Later, rats were sacrificed and gastric tissue samples were excised.

Low dose therapy group: $40 \mathrm{mg} / \mathrm{kg}$ of caftaric acid was administered by oral gavage $30 \mathrm{~min}$ before the indomethacin application.

High dose therapy group: $80 \mathrm{mg}$ of caftaric acid was administered $30 \mathrm{~min}$ before the indomethacin application. The stomachs were removed, and the ulcer areas on the gastric surfaces were examined macroscopically.

\section{Macroscopic examination of gastric tissue}

To determine the gastric lesions, rat stomachs were macroscopically evaluated, and the number of ulcers with the areas were determined. The size of each ulcer area was measured using millimetric paper (Guidobono et al. 1997).

\section{Analysis of biochemical parameters}

Malondialdehyde (MDA) level in stomach tissue homogenate was determined according to Ohkawa et al. (1979). Total antioxidant status (TAS) value was detected with the commercial kit (Rel Assay Diagnostics). Total oxidant status (TOS) measurement was applied with commercially available kit (Rel Assay Diagnostics). The ratio of TOS/TAS was accepted as the oxidative stress index (OSI). OSI value was calculated as follows: OSI $=\left[\left(\mathrm{TOS}, \mu \mathrm{mol} \mathrm{H}_{2} \mathrm{O}_{2}\right.\right.$ equivalent /1)/(TAS, mmol Trolox equivalent/l $) \times 10$ ]. We used OSI as an another indicator of oxidative stress. TNF- $\alpha$ and IL- $1 \beta$ 


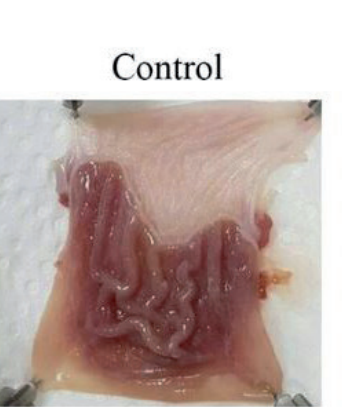

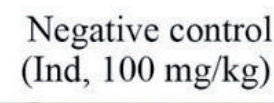

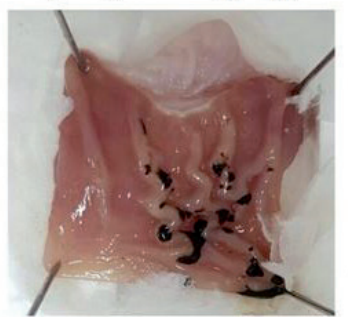

Positive control (Ome, $30 \mathrm{mg} / \mathrm{kg}$ )

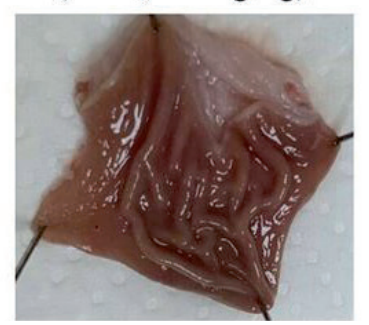

Low dose theraphy High dose theraphy (CA, $40 \mathrm{mg} / \mathrm{kg}$ )

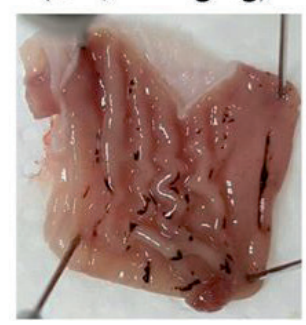

(CA, $80 \mathrm{mg} / \mathrm{kg}$ )

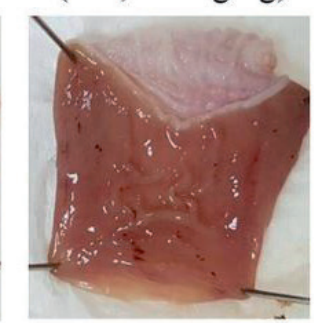

Figure 1. Gastroprotective effects of low (40 mg/kg) and high ( $80 \mathrm{mg} / \mathrm{kg})$ dose of caftaric therapy (CA) on gastric ulcer induced by indomethacin (Ind). Ome, omeprazole.

were analysed with commercially available kit. The kits were purchased from Glory Science Co., Ltd (Zhejiang, People's Republic of China). Myeloperoxidase (MPO) activity in gastric tissue samples was evaluated by using method of Bradley et al. (1982).

\section{Statistical analysis of data}

All results were presented as the mean \pm standard error of the mean (SEM). Statistical significant differences were defined using one-way ANOVA with the Tukey HSD for multiple comparisons. The values of $p<0.05$ were considered as statistically significant.

\section{Results}

Indomethacin application caused ulcer in gastric mucosa. Positive control group demonstrated a considerable decrease in the size of gastric ulcer areas compared with negative control group $(p<0.05)$. Low and high doses of caftaric acid administration significantly reduced the size of the gastric ulcer areas as in omeprazole group compared with negative control group $p<0.05)$. But in the high dose therapy group, there was further shrinkage in the size of ulcer areas macroscopically compared with low dose therapy group (see Fig. 1, 4). In negative control group, TOS and OSI values increased and TAS values decreased. TOS and OSI values decreased significantly in the groups with either omeprazole or low and high dose of caftaric acid compared with negative control group $(p<0.05)$ (Table 1). As demonstrated in Fig. $2 \mathrm{~A}$ and $\mathrm{B}, \mathrm{MDA}$ level and MPO activity in negative control group indicated a significant increase compared with control group $(p<0.05)$. On the other hand, these oxidants reduced importantly in positive control, low and high dose therapy groups $(p<0.05)$ compared with negative control group $(p<0.05)$. The high dose administration of caftaric acid more reduced the MPO activity and MDA level than the low dose therapy group. In negative control group, due to indomethacin administration, TNF-a and IL-b levels increased compared with the other groups. Administration of either
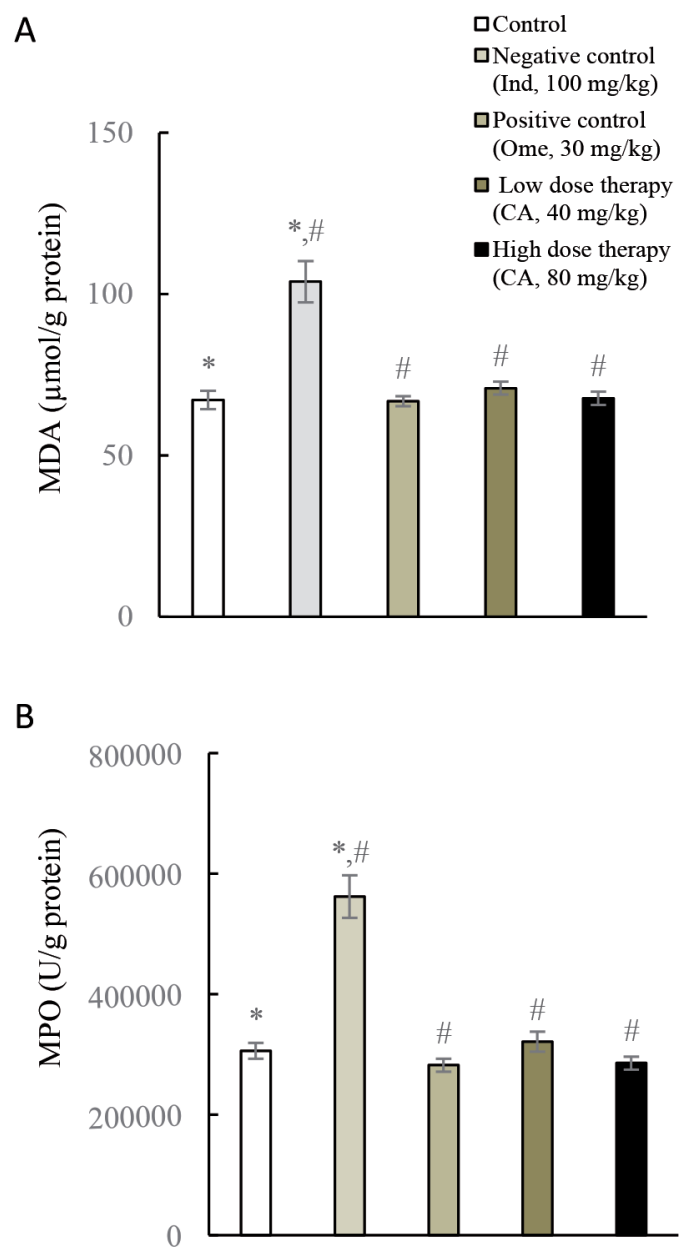

Figure 2. The levels of malondialdehyde (MDA; $\mathbf{A})$ and myeloperoxidase (MPO; B) in all groups. ${ }^{\star} p<0.05$ vs. Control group; ${ }^{\#} p<$ $0.05 v s$. Negative control group. For more abbreviations, see Fig. 1. 
Table 1. TAS, TOS and OSI values of all experimental groups were presented as mean \pm SEM

\begin{tabular}{lccc}
\hline Group & $\begin{array}{c}\text { TAC } \\
(\mathrm{mmol} / \mathrm{mg} \text { protein })\end{array}$ & $\begin{array}{c}\text { TOS } \\
(\mu \mathrm{mol} / \mathrm{mg} \text { protein })\end{array}$ & OSI (TAC/TOS $\left.{ }^{*} 10\right)$ \\
\hline Control & $4.65 \pm 0.25$ & $17.54 \pm 0.42$ & $67.24 \pm 2.84$ \\
Negative control (Ind 100 mg/kg) & $2.25 \pm 0.20^{\star}$ & $32.71 \pm 1.11^{\star}$ & $103.86 \pm 6.41^{\star}$ \\
Positive control (Ome $30 \mathrm{mg} / \mathrm{kg})$ & $4.69 \pm 0.28^{\#}$ & $16.86 \pm 0.58^{\#}$ & $66.78 \pm 1.55^{\#}$ \\
Low dose theraphy (CA 40 mg/kg) & $3.82 \pm 0.21^{\#}$ & $19.63 \pm 0.45^{\#, \$}$ & $70.85 \pm 2.02^{\#}$ \\
High dose theraphy (CA 80 mg/kg) & $4.55 \pm 0.23^{\#}$ & $17.09 \pm 0.42^{\#}$ & $67.71 \pm 2.02^{\#}$ \\
\hline
\end{tabular}

${ }^{*} p<0.05 v s$. Control group; ${ }^{*} p<0.05 v s$. Negative control group; ${ }^{\$} p<0.05 v s$. Positive control group. TAC, total antioxidant status; TOC, total oxidant status; OSI, oxidative stress index; Ind, indomethacin; Ome, omeprazol; CA, caftaric acid.

omeprazole or low and high dose of caftaric acid decreased TNF- $\alpha$ and IL- $1 \beta$ levels significantly compared with negative control group (Fig. 3A, B; $p<0.05$ ). These findings show that low and high doses of caftaric acid have an antioxidant and

A

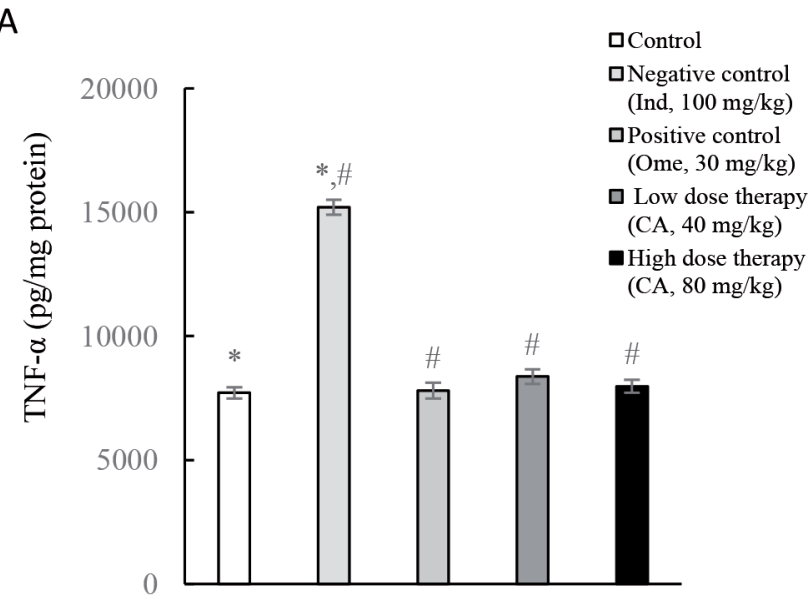

B

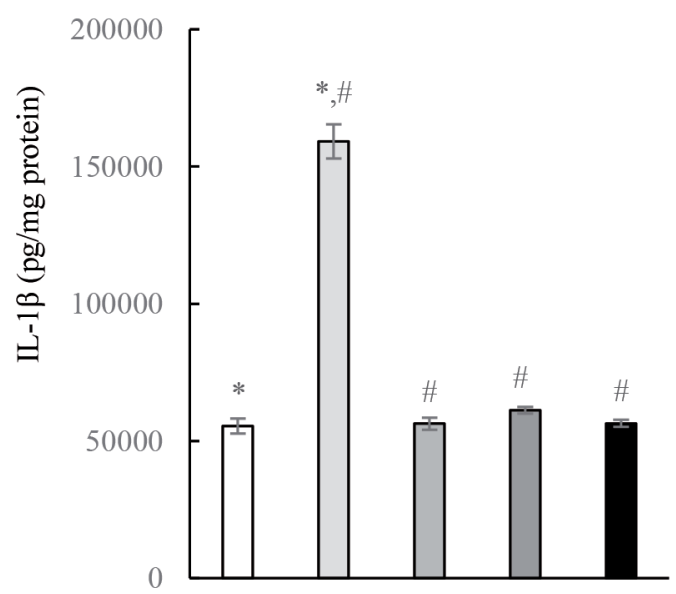

Figure 3. The levels of TNF- $\alpha$ (A) and IL-1 $\beta$ (B) in all groups. ${ }^{*} p<0.05$ vs. Control group; ${ }^{\#} p<0.05 v$ s. Negative control group. For abbreviations, see Fig. 1. anti-inflammatory effects against indomethacin-induced oxidative damage.

\section{Discussion}

Gastric ulcer is one of the most common medical topics among the all gastrointestinal disorders, globally affecting $10 \%$ people and especially including developed countries with yearly prevalence in rates of $0.1-0.19 \%$ (Sung et al. 2009). This problem results in chronic pain, loss of appetite, weight, and work power. The disease may lead to upper gastrointestinal hemorrhage and perforation which have high mortality and morbidity rates (Khushtar et al. 2009; Golbabapour et al. 2013). There are many etiologic causes of gastric ulcer. Various factors such as burns, stress, sepsis, hemorrhagic shock, alcohol consumption, smoking, trauma, non- steroidal drugs, pulmonary and liver diseases have been shown to play a role in gastric ulcerogenesis (Di 2000; Brzozowski et al. 2005; Suleyman et al. 2009). Indomethacin, a member of-of NSAIDs, has anti-inflammatory, antipyretic, and analgesic properties and leads to serious side effects such as erosion, ulcerative lesions and petechial haemorrhage in stomach. In addition, the progression and development of gastric mucosal lesions induced by indomethacin occurs primarily through the formation of oxygen free radicals (Teichert et al. 2014). The increase in ROS generation plays an important role in pathogenesis of a large number of inflammatory diseases such as abdominal pathologies, peptic ulcers (Saranya and Geetha 2011). Moreover, ROS generation and lipid peroxidation play a key role in the improvement of the gastric mucosal damage caused by indomethacin (Kim et al. 2011). Under normal conditions, ROS are cleared and neutralized by the endogenous antioxidant cellular system such as glutathione (GSH), catalase (CAT) and superoxide dismutase (SOD) (Halliwell and Gutteridge 1990). However, when ROS production is excessively increased and the cellular antioxidant defence system is inadequate to remove these produced oxidants, oxidative stress occurs. As a result of 


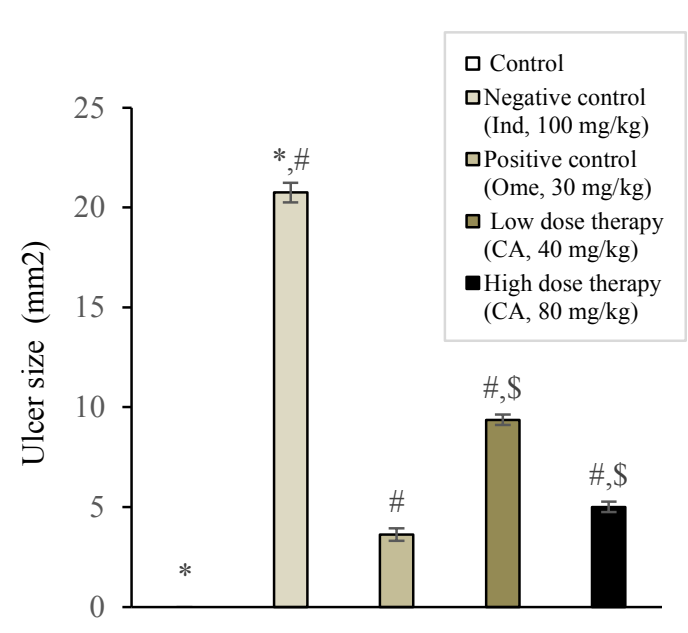

Figure 4. The size of gastric ulcer in all groups. ${ }^{\star} p<0.05 v$ s. Control group; ${ }^{\#} p<0.05$ vs. Negative control group; ${ }^{\$} p<0.05 v s$. Positive control group. For abbreviations, see Fig. 1.

oxidative stress, lipid peroxidation starts due to the attack of free radicals on cellular lipids. One of the end products of lipid peroxidation is MDA (Halliwell and Gutteridge 1990). Nearly all of the studies about indomethacin-induced ulcer show an increase in MPO or MDA level in the gastric tissues due to indomethacin-application (Naito et al. 1998; Miura et al. 2002; Thong-Ngam et al. 2012). It is also aimed to reduce MDA levels triggered by indomethacin-induced gastric damage using a large number of antioxidant agents (Kim et al. 2011; Khushtar et al. 2016; Gomaa et al. 2018). Koriem and Salman declared that caftaric acid protects the liver by increasing antioxidant enzymes and reducing MDA level against methamphetamine-induced oxidative stress (Koriem and Soliman 2014). Khushtar and colleagues evaluated antioxidant levels such as SOD, GSH and CAT and reported that these antioxidant enzyme activities were markedly reduced in indomethacin-treated group (Khushtar et al. 2009). Again, Gomaa et al. showed that TAS value significantly diminished in gastric ulcerated tissues induced by indomethacin (Gomaa et al. 2018). These findings are supported by our study results that MDA level, TOS and OSI values increased but TAS value decreased in negative control group by single gavage indomethacin administration compared with control group. In contrast, low and high dose of caftaric acid therapy reduced MDA level, TOS, OSI values and increased TAS value compared with negative control group. So, caftaric acid attenuated the lipid peroxidation process and supported the antioxidant defence in experimental animals. TNF- $\alpha$ is one of the pro-inflammatory cytokines and a key determiner of NSAID-induced peptic/ gastric ulcer. Mostly, an increasing in the level of TNF- $\alpha$ is regarded as a detrimental index for the gastrointestinal system (Fukumoto et al. 2011).
IL- $1 \beta$ is defined as an another pro-inflammatory cytokine produced by activated macrophages and often considered as a distinguishing feature of inflammatory gene cascades (Weber et al. 2010). It has also been shown that TNF-a level is markedly elevated in indomethacin-induced gastric ulcer (Wu et al. 2018). In our study, high levels of the TNF- $\alpha$ and IL- $1 \beta$ were found in the ulcer tissues after the indomethacin application, but these values were low by the high and low dose of caftaric acid therapy compared with negative control group.

\section{Conclusion}

In the light of the findings acquired by our study, it can say that both low and high dose of caftaric acid administration attenuated the gastric ulcer and supported the recovery. It can also think that caftaric acid may be performed antiinflammatory and antioxidant effects by decreasing oxidant parameter levels, increasing the antioxidant capacity and reducing pro-inflammatory cytokine levels.

Conflict of interest. The authors declare that there are no conflicts of interest.

\section{References}

Barrett B (2003): Medicinal properties of Echinacea, a critical review. Phytomed. 10, 66-86 https://doi.org/10.1078/094471103321648692

Bradley PP, Priebat DA, Christensen RD, Rothstein G (1982): Measurement of cutaneous inflammation, estimation of neutrophil content with an enzyme marker. J. Invest. Dermatol. 78, 206-209 https://doi.org/10.1111/1523-1747.ep12506462

Brzozowski T, Konturek PC, Konturek SJ, Brzozowska I, Pawlik T (2005): Role of prostaglandins in gastroprotection and gastric adaptation. J. Physiol. Pharmacol. 56, 33-55

Cundy T, Dissanayake A (2008): Severe hypomagnesaemia in long-term users of proton-pump inhibitors. Clin. Endocrinol. 69, 338-341 https://doi.org/10.1111/j.1365-2265.2008.03194.x

Di MA (2000): Therapy of digestive disorders, A companion to slinger and Fordtran's gastrointestinal and liver disease. Gastroenterol. 118, 1275-1276

El-Komya MM, Mouafib FE (2016): Mitigating effect of Avicenna marina on indomethacin-induced gastric ulcer in male albino rats. Egypt J. Basic Appl. Sci. 3, 155-163

Fukumoto K, Naito Y, Takagi T, Yamada S, Horie R, Inoue K, Harusato A, Hirata I, Omatsu T, Mizushima K, et al. (2011): Role of tumor necrosis factor-alpha in the pathogenesis of indomethacin-induced small intestinal injury in mice. Int. J. Mol. Med. 27, 353-359

Golbabapour S, Hajrezaie M, Hassandarvish P, Majid NA, Hadi AHA, Nordin N and Abdulla MA (2013): Acute toxicity and 
gastroprotective role of $\mathrm{m}$. pruriens in ethanol-induced gastric mucosal injuries in rats. Biomed. Res. Int. 2013, 1509057 https://doi.org/10.1155/2013/974185

Gomaa AMS, Abd El-Mottaleb NA, Aamer HA (2018): Antioxidant and anti-inflammatory activities of alpha lipoic acid protect against indomethacin-induced gastric ulcer in rats. Biomed. Pharmacother. 101, 188-194

https://doi.org/10.1016/j.biopha.2018.02.070

Graham DY, Genta RM (2008): Long-term proton pump inhibitor use and gastrointestinal cancer. Curr. Gastroenterol. Rep. 10, 543-547 https://doi.org/10.1007/s11894-008-0100-1

Gray SL, LaCroix AZ, Larson J, Robbins J, Cauley JA, Manson JE, Chen Z (2010): Proton pump inhibitor use, hip fracture, and change in bone mineral density in postmenopausal women, results from the Women's Health Initiative. Arch. Intern. Med. 170, 765-771 https://doi.org/10.1001/archinternmed.2010.94

Guidobono F, Pagani F, Ticozzi C, Sibilia V, Pecile A, Netti C (1997): Protection by amylin of gastric erosions induced by indomethacin or ethanol in rats. Br. J. Pharmacol. 120, $581-586$ https://doi.org/10.1038/sj.bjp.0700941

Halliwell B, Gutteridge JM (1990): Role of free radicals and catalytic metal ions in human disease, an overview. Methods Enzymol. 186, $1-85$ https://doi.org/10.1016/0076-6879(90)86093-B

Howden CW (2000): Vitamin B12 levels during prolonged treatment with proton pump inhibitors. J. Clin. Gastroenterol. 30, 29-33 https://doi.org/10.1097/00004836-200001000-00006

Khushtar M, Kumar V, Javed K, Bhandari U (2009): Protective effect of ginger oil on aspirin and pylorus ligation-induced gastric ulcer model in rats. Indian J. Pharma. Sci. 71, 554-558 https://doi.org/10.4103/0250-474X.58195

Khushtar M, Siddiqui HH, Dixit RK, Khan MS, Iqbal D, Rahman MA (2016): Amelioration of gastric ulcers using a hydroalcoholic extract of Triphala in indomethacin-induced Wistar rats. Eur. J. Integr Med. 8, 546-551 https://doi.org/10.1016/j.eujim.2016.01.004

Kim JH, Kim BW, Kwon HJ, Nam SW (2011): Curative effect of selenium against indomethacin-induced gastric ulcers in rats. J. Microbiol. Biotechnol. 21, 400-404

Koriem KM., Soliman RE (2014): Chlorogenic and caftaric acids in liver toxicity and oxidative stress induced by methamphetamine. J. Toxicol. 2014, 583494 https://doi.org/10.1155/2014/583494

Liu YH, Zhang ZB, Zheng YF, Chen HM, Yu XT, Chen XY, Zhang X, Xie JH, Su ZQ, Feng XX, et al. (2015): Gastroprotective effect of andrographolide sodium bisulfite against indomethacininduced gastric ulceration in rats. Int. Immunopharmacol. 26, 384-391

https://doi.org/10.1016/j.intimp.2015.04.025

Miura T, Muraoka S, Fujimoto Y (2002): Lipid peroxidation induced by indomethacin with horseradish peroxidase and hydrogen peroxide, involvement of indomethacin radicals. Biochem. Pharmacol. 63, 2069-2074 https://doi.org/10.1016/S0006-2952(02)00995-4
Naito Y, Yoshikawa T, Yoshida N, Kondo M (1998): Role of oxygen radical and lipid peroxidation in indomethacin-induced gastric mucosal injury. Dig. Dis. Sci. 43, 30-34

Niklasson A, Lindstrom L, Simren M, Lindberg G, Bjornsson E (2010): Dyspeptic symptom development after discontinuation of a proton pump inhibitor, a double-blind placebo-controlled trial. Am. J. Gastroenterol. 105, 1531-1537 https://doi.org/10.1038/ajg.2010.81

Ohkawa H, Ohishi N, Yagi K (1979): Assay for Lipid Peroxides in Animal-Tissues by Thiobarbituric Acid Reaction. Anal. Biochem. 95, 351-358 https://doi.org/10.1016/0003-2697(79)90738-3

Pineda-Pena EA, Martinez-Perez Y, Galicia-Moreno M, Navarrete A, Segovia J, Muriel P, Favari L, Castaneda-Hernandez G, Chavez-Pina AE (2018): Participation of the anti-inflammatory and antioxidative activity of docosahexaenoic acid on indomethacin-induced gastric injury model. Eur. J. Pharmacol. 818, 585-592 https://doi.org/10.1016/j.ejphar.2017.11.015

Raso GM, Pacilio M, Di Carlo G, Esposito E, Pinto L, Meli R (2002): In-vivo and in-vitro anti-inflammatory effect of Echinacea purpurea and Hypericum perforatum. J. Pharm. Pharmacol. 54, 1379-1383 https://doi.org/10.1211/002235702760345464

Richardson P, Hawkey CJ, Stack WA (1998): Proton pump inhibitors - Pharmacology and rationale for use in gastrointestinal disorders. Drugs 56, 307-335

https://doi.org/10.2165/00003495-199856030-00002

Saranya P, Geetha A (2011): Antiulcer activity of Andrographis paniculata (Burm.f.) Wall. against cysteamine-induced duodenal ulcer in rats. Indian J. Exp. Biol. 49, 525-533

Simmons DL, Botting RM, Hla T (2004): Cyclooxygenase isozymes, The biology of prostaglandin synthesis and inhibition. Pharmacol. Rev. 56, 387-437 https://doi.org/10.1124/pr.56.3.3

Suleyman H, Cadirci E, Albayrak A, Polat B, Halici Z, Koc F, Hacimuftuoglu A, Bayir Y (2009): Comparative study on the gastroprotective potential of some antidepressants in indomethacin-induced ulcer in rats. Chem. Biol. Interact. 180, 318-324 https://doi.org/10.1016/j.cbi.2009.03.002

Suleyman H, Albayrak A, Bilici M, Cadirci E, Halici Z (2010): Different mechanisms in formation and prevention of indomethacin-induced gastric ulcers. Inflam. 33, 224-234 https://doi.org/10.1007/s10753-009-9176-5

Sung JJ, Kuipers EJ, El-Serag HB (2009): Systematic review, the global incidence and prevalence of peptic ulcer disease. Aliment. Pharmacol. Ther. 29, 938-946 https://doi.org/10.1111/j.1365-2036.2009.03960.x

Teichert M., Griens F, Buijs E, Wensing M, De Smet PAGM. (2014): Effectiveness of interventions by community pharmacists to reduce risk of gastrointestinal side effects in nonselective nonsteroidal anti-inflammatory drug users. Pharmacoepidemiol. Drug Saf. 23, 382-389 https://doi.org/10.1002/pds.3587

Thong-Ngam D, Choochuai S, Patumraj S, Chayanupatkul M, Klaikeaw N (2012): Curcumin prevents indomethacin-induced gastropathy in rats. World J. Gastroenterol. 18, 1479-1484 https://doi.org/10.3748/wjg.v18.i13.1479 
Wallace JL (2013): Mechanisms, prevention and clinical implications of nonsteroidal anti-inflammatory drug-enteropathy. World J. Gastroenterol. 19, 1861-1876 https://doi.org/10.3748/wjg.v19.i12.1861

Wallace JL, Syer S, Denou E, de Palma G, Vong L, McKnight W, Jury J, Bolla M, Bercik P, Collins SM, et al. (2011): Proton pump inhibitors exacerbate NSAID-induced small intestinal injury by inducing dysbiosis. Gastroenterol. 141, 1314-1322 https://doi.org/10.1053/j.gastro.2011.06.075

Weber A, Wasiliew P, Kracht M (2010): Interleukin-1 (IL-1) pathway. Sci. Signal. 105, 1

Wu JZ, Liu YH, Liang JL, Huang QH, Dou YX, Nie J, Zhuo JY, Wu X, Chen JN, Su ZR, Wu QD (2018): Protective role of betapatchoulene from Pogostemon cablin against indomethacininduced gastric ulcer in rats, Involvement of anti-inflammation and angiogenesis. Phytomed. 39, 111-118 https://doi.org/10.1016/j.phymed.2017.12.024

Yearsley KA, Gilby LJ, Ramadas AV, Kubiak EM, Fone DL, Allison MC (2006): Proton pump inhibitor therapy is a risk factor for Clostridium difficile-associated diarrhoea. Aliment. Pharmacol. Ther. 24, 613-619 https://doi.org/10.1111/j.1365-2036.2006.03015.x

Zheng YF, Xie JH, Xu YF, Liang YZ, Mo ZZ, Jiang WW, Chen XY, Liu YH, Yu XD, Huang P, Su ZR (2014): Gastroprotective effect and mechanism of patchouli alcohol against ethanol, indomethacin and stress-induced ulcer in rats. Chem. Biol. Interact. 222, 27-36

https://doi.org/10.1016/j.cbi.2014.08.008

Received: May 17, 2018

Final version accepted: August 17, 2018

First published online: March 1, 2019 